\title{
Energy shift estimation of demand response activation on domestic refrigerators - A field test study
}

Lakshmanan, Venkatachalam; Gudmand-Høyer, Kristian; Marinelli, Mattia; Kosek, Anna Magdalena; Nørgård, Per Bromand

\section{Published in:}

Proceedings of the 49th International Universities Power Engineering Conference (UPEC 2014)

Link to article, DOI:

10.1109/UPEC.2014.6934681

Publication date:

2014

Link back to DTU Orbit

Citation (APA):

Lakshmanan, V., Gudmand-Høyer, K., Marinelli, M., Kosek, A. M., \& Nørgård, P. B. (2014). Energy shift estimation of demand response activation on domestic refrigerators - A field test study. In Proceedings of the 49th International Universities Power Engineering Conference (UPEC 2014) IEEE.

https://doi.org/10.1109/UPEC.2014.6934681

\section{General rights}

Copyright and moral rights for the publications made accessible in the public portal are retained by the authors and/or other copyright owners and it is a condition of accessing publications that users recognise and abide by the legal requirements associated with these rights.

- Users may download and print one copy of any publication from the public portal for the purpose of private study or research.

- You may not further distribute the material or use it for any profit-making activity or commercial gain

- You may freely distribute the URL identifying the publication in the public portal 


\title{
Energy Shift Estimation of Demand Response Activation on Refrigerators - A Field Test Study
}

\author{
Venkatachalam Lakshmanan, Kristian Gudmand-Høyer, Mattia Marinelli, Anna Magdalena Kosek, Per Nørgård \\ Department of Electrical Engineering (Center for Electric Power and Energy), DTU - Technical University of Denmark \\ Contact Person: Venkatachalam Lakshmanan, vela@elektro.dtu.dk
}

\begin{abstract}
This paper presents a method to estimate the amount of energy that can be shifted during demand response (DR) activation on domestic refrigerator. Though there are many methods for DR activation like load reduction, load shifting and onsite generation, the method under study is load shifting. Electric heating and cooling equipment like refrigerators, water heaters and space heaters and coolers are preferred for such DR activation because of their energy storing capacity. Accurate estimation of available regulating power and energy shift is important to understand the value of $D R$ activation at any time. In this paper a novel method to estimate the available energy shift from domestic refrigerators with only two measurements, namely fridge cool chamber temperature and compressor power consumption is proposed, discussed and evaluated.
\end{abstract}

Index Terms-- Demand Response, Energy estimation, Field experiment, Load shifting.

\section{INTRODUCTION}

The shift from consumption based production to production driven consumption is driven by the increasing percentage of unpredictable renewable resources. The large centralized traditional power plants are being replaced with many small distributed production units. Danish ambition is to move from $21 \%$ of wind and solar production in 2010[1] to $50 \%$ consumption being supplied from wind is set for 2020 [2]. A large amount of uncontrollable renewable production brings several challenges for future power systems. Production fluctuations influences power system stability, in expected days with low wind and sun power system require energy storage facilities or shiftable consumption [3]. The solution offered by Demand Response (DR) suggests that resources that can be used for power system balancing can be found on the demand side rather only in the supply side [4].In DR demand is adjusted either by load reduction, increase or shifting. DR includes all controllable loads with ability to differ consumption without compromising the quality of service delivered to the user.

Consumption form both residential and commercial buildings accounts to $34 \%$ of total consumption in Nordic countries. Residential houses account to two-thirds of this amount and within the houses all appliances consume around $17 \%$ of total energy [5]. Domestic appliances considered to be suitable for load shifting are fridges, freezers, dishwashers, washing machines and driers. Among these devices only fridges have periodical operation and thermal capacity, making it more suitable for time-of-the day independent load shifting. A fridge is also available in most of households and it's the most important objective: keeping a low temperature, is easily measurable with a simple temperature sensor. An assessment for fridges and freezers for smart consumer load participation have already been done [6]. The remote control of refrigerator for demand side participation is demonstrated in [7].

In [8] simulated domestic fridges were used to stabilize the grid frequency. In this work a fridge model based on a data from a single fridge was used to simulate 1000 fridges. The flexibility of a fridge was based on a model of appliance without any disturbances, for example opening the ridge door, adding and removing the load. An adaptive model based on the historical data of a single fridge was presented in [9]. The model presented in [9] estimates thermostatic cycles of the fridge based on a recent cycle taking under consideration recent disturbances. In [10] a fridge thermostat cycles are shifted based on the electricity price. In this work a fridge is assumed to have the same flexibility during all time, which is a size of one thermostat cycle. In reality there are more factors influencing the flexibility of a fridge and amount of energy that can be shifted.

The aim of this paper is to present a simple method to estimate the amount of energy that can be shifted during demand response (DR) activation on domestic refrigerator using the temperature prediction strategy given in [9]. The method will be validated on real refrigerator units in 10 domestic households, which work at different indoor and ambient temperatures and under different thermal load conditions. The rest of this paper is organized as follows: in Section II the principle of the estimation method and problem outline are introduced, and the control strategy adopted for energy reduction is briefly presented. Section III explains the experiment platform, hardware devices used for control and measurement and their configuration. Section IV discusses about the control strategy, practical limitations and safety constraints in detail. The results of the experiments are discussed in section $\mathrm{V}$ and the conclusions and future work are reported in section VI.

\section{MethodOLOGY}

The refrigerator temperature swings between two temperature levels namely higher threshold (HT) and lower threshold (LT) controlled by the internal thermostat as shown in the Fig. 1. The temperature set by the user namely the set point can be considered as the temperature in between these two threshold temperatures. The fridge cool chamber temperature depends 
on different parameter like compressor run time, thermal mass of the food content inside, ambient temperature, thermal insulation of the envelope material and user interaction which alters the thermal mass due to food and air exchange. Predicting cool chamber temperature is the only way to predict the energy consumption by the compressor, as the temperature prediction can provide compressor runtime. There are varieties of refrigerator models available to predict the temperature of the refrigerator's cool chamber [9], [11].
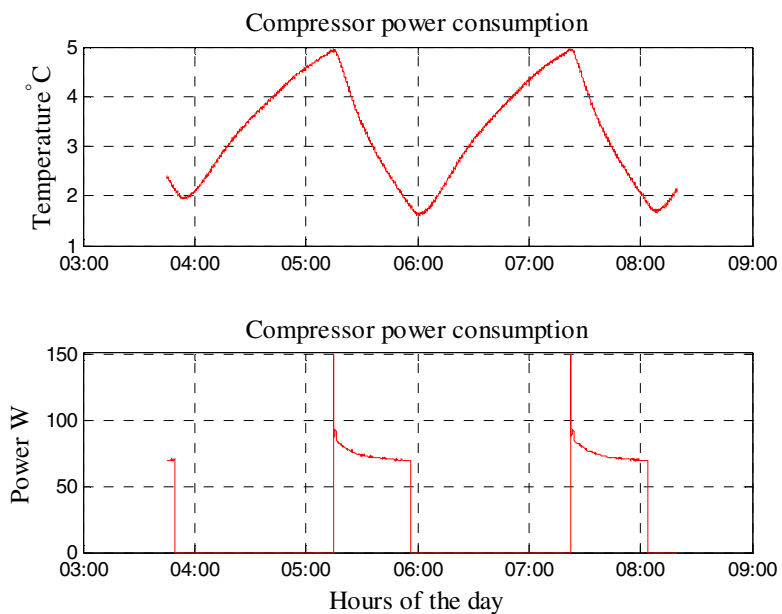

Fig. 1 Refrigerator cool chamber temperature variation and compressor power consumption.

More details the model has more complex the model will be and tailored for a particular refrigerator. A detailed model needs to produce accurate prediction results when the dynamics of the refrigerator are changing. The change in the refrigerator dynamics are predominantly due to change in thermal mass when the food is exchanged and also due to change in ambient temperature. A detailed thermal modelling of household refrigerator is presented in [12]. When the dynamics of the refrigerator are not changing, a simple model [9] can predict the refrigerator cool chamber temperature with considerable accuracy during the cooling and heating cycles. The temperature prediction enables predicting the duration it takes to reach a particular temperature in heating or cooling cycle. If the temperature durations are predicted, then the compressor $\mathrm{ON}$ and OFF time can be estimated. From the compressor power and ON/OFF time, the amount of energy that is consumed and the amount that can be shifted can be estimated.

The proposed method maintains the cool chamber temperature at $\Delta \mathrm{T}$ degree above the HT during the demand response activation duration $\left(t_{D R}\right)$ in order to have minimum impact on quality of service. The quality of service is maintenance of cool chamber temperature as much as close to the set point temperature. The overall objective is to reduce energy consumption by maintaining the fridge temperature close to HT by reducing the compressor ON time. As explained in the black box model [9], the heating and cooling cycle duration and their dynamics don't change much compare to their previous cycles. The different heating $\left(t_{\mathrm{he}}\right)$ and cooling time $\left(t_{c e}\right)$ during DR activation can be extracted from the previous heating and cooling cycles as shown in Fig. 2. The energy consumption during DR activation can be estimated by integrating corresponding compressor power (CP) over that time. The number of cycles and the associated energy consumption can be calculated as follows:

- Number of heating and cooling cycles $\mathrm{N}=\left(\mathrm{t}_{\mathrm{DR}}\right.$ $\left.t_{\text {hea }}\right) /\left(t_{\text {he }}+t_{c e}\right)$

- Energy consumption during DR activation $\mathrm{E}_{\mathrm{DR}}=\mathrm{N}$ $\mathrm{x}\left(\mathrm{CP} \times \mathrm{t}_{\mathrm{ce}}\right)$

- $\quad$ Estimated energy shift $\mathrm{E}_{\mathrm{s}}=\mathrm{E}_{\mathrm{preDR}}-\mathrm{E}_{\mathrm{DR}}$

Where $t_{\text {hea }}$ is the time elapsed during initial heating time at the beginning of DR activation.

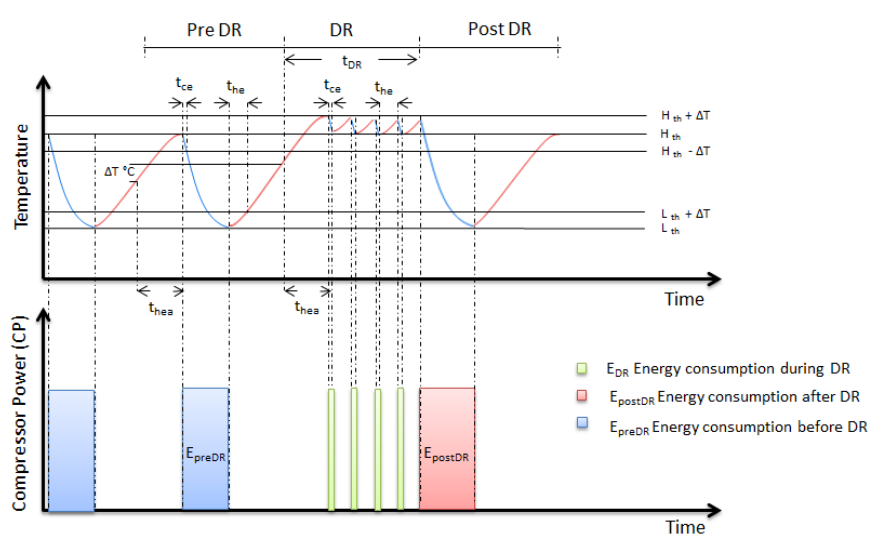

Fig. 2 Refrigerator energy consumption estimation during demand response activation

\section{EXPERIMENTAL PROCEDURE}

\section{A. Experimental setup}

The experiment was conducted on the INCAP project platform which facilitates the control of domestic refrigerators. The INCAP project platform connects multiple domestic consumers' refrigerators to a control server. Ten fridges from selected households were considered for the control. The block diagram of the setup in one household is shown in the Fig. 3. There are four devices used for sensing and control purpose. They are

1. Contact unit which switches the fridge ON and OFF in response to the command from remote.

2. Temperature-light - PIR sensor which senses temperature, light and human occupancy.

3. A user interface device with red and green lights and two buttons.

4. A Zigbee- Ethernet gateway device for communication with the control server.

All these devices are part of Zigbee wireless home automation network products commercially available from a manufacturer Develco Products A/S. In Zigbee wireless network environment, the network is hosted by a network coordinator. In this experiment, the Zigbee- Ethernet gateway device is the network coordinator. All other devices are connected to the network as a Zigbee end device as 
authorized by the control server. The Zigbee- Ethernet gateway device is connected to the control server through a wired broad band ADSL internet connection. All these devices send and receive data from the control server through the Zigbee- Ethernet gateway device. The temperature sensor and the user interface device are battery powered devices while the contact unit and the Zigbee- Ethernet gateway device are powered from mains supply.

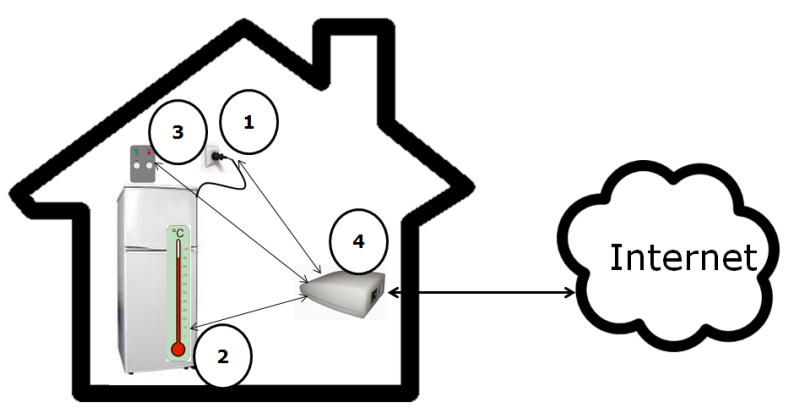

Fig. 3 Refrigerator control device installation in single house

These devices were sent to the fridge owners for installation and were installed by them as per the instruction manual attached. The Zigbee- Ethernet gateway device is connected to mains supply for power and to one of the Ethernet ports of ADSL modem for communication with control server. The contact unit was connected in series with power input of the refrigerator.

The temperature sensor was placed inside the cool chamber of the refrigerator. The user indicator can be placed anywhere in the user's vicinity. On installation, the control server receives the joining requests from all devices. The control server verifies the addresses of these devices with the data base and authorizes them to join the network. Once the devices are joined in the network, they are configured for measurement sampling rate.

\section{B. Measurement parameters and sampling rate}

Temperature: To have a long battery life span, the temperature sensor has a sampling restriction of 2 minutes which cannot be modified. It sends the temperature and light measurements every 2 minutes and the occupancy information as event driven message. The temperature sensor has an accuracy of $\pm 0.5{ }^{\circ} \mathrm{C}$ and a resolution of $1 / 6{ }^{\circ} \mathrm{C}$. The light sensor reports the light measurement in lux.

Active power and voltage: The contact unit has ability to measure active power consumption at 1 watt resolution and RMS value of line voltage at 1 volt resolution. This device was configured to send the measurement every 10 seconds. The 10 seconds interval was selected in trial and error to avid network data congestions.

All configuration details were stored permanently in the non-volatile memory of these devices. On configuration the devices send measured parameters to the control server in a form of short messages. The received data were stored in a temporary array for control purpose and in a SQL data base for the future data analysis. The next section describes the controller for DR activation and the additional necessary software components for control commands and measurement data communication.

\section{CONTROLler DESCRIPTION}

\section{A. Controller architecture}

The refrigerators are controlled by a central controller. The central controller is a JAVA program executed in a virtual windows machine acquired from the central server of DTU. The sever hosts a software called Smart AMM server given by the company Develco Products A/S who provide control devices for the experiment. Smart AMM server establishes the data connection between the devices and controller. A block diagram of the data flow is shown in the Fig. 4.

The devices, which are connected to the refrigerators, send all measurement data in a form of short messages to the Smart AMM server. Any client software that is subscribed to the Smart AMM Server can get a copy of these messages. Similarly the client software also can send command and configuration messages to the devices through the Smart AMM Server.

\section{B. Fridge temperature and controlling capability}

The control software receives temperature measurement message every two minutes and the voltage and power measurement data every ten seconds. The temperature measurement corresponding to the higher threshold which is the maximum value at the end of previous heating cycle for every refrigerator is stored locally in the program. Similarly the temperature measurement corresponding to the lower threshold which is the minimum value at the end of previous cooling cycle for every refrigerator is stored locally in the program. The heating and cooling cycles were identified from the fridge power measurement message.

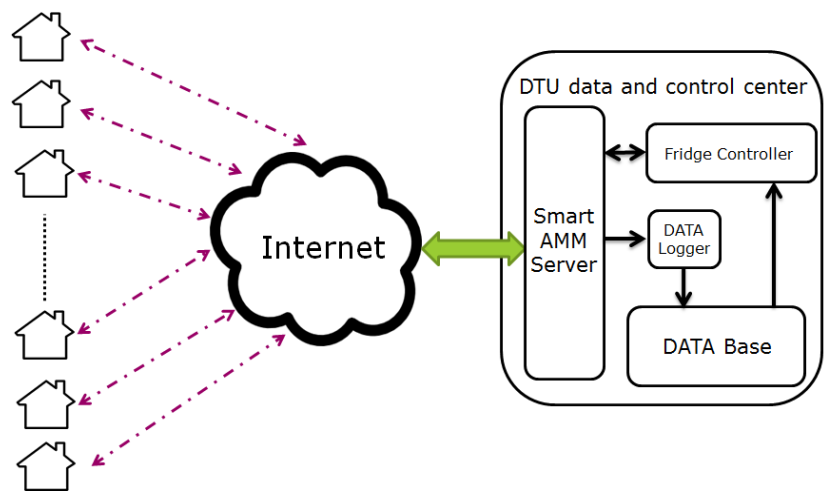

Fig. 4 Data flow from the houses to the central server.

During cooling, the compressor is activated and running. There is definite power consumption during the compressor operation. During heating cycle the compressor is switched off by the internal thermostat and consumes no power. There is a possibility of power consumption during heating cycle while the compressor is off by the internal light bulb. The 
light bulb is illuminated when the fridge door is opened. While considering heating and cooling cycle identification, power measurements above 30 watts are considered to avoid the confusions caused by the power consumption by the light bulb when the fridge door is opened. The controller has the following functions.

1. During the demand response time, the controller maintains the fridge cool chamber temperature between the maximum threshold and $\Delta \mathrm{T}$ above maximum threshold.

2. If the refrigerator door is opened during the demand response period, the control relay is switched ON for a short period of 5 minutes to illuminate the light bulb to avoid the inconvenience to the user.

3. A five minutes of switch OFF time is maintained before switching ON the compressor on every compressor shut off to avoid compressor damage by the evaporator back pressure. The user has an option to avoid his/her fridge to be controlled for another 24 hours.
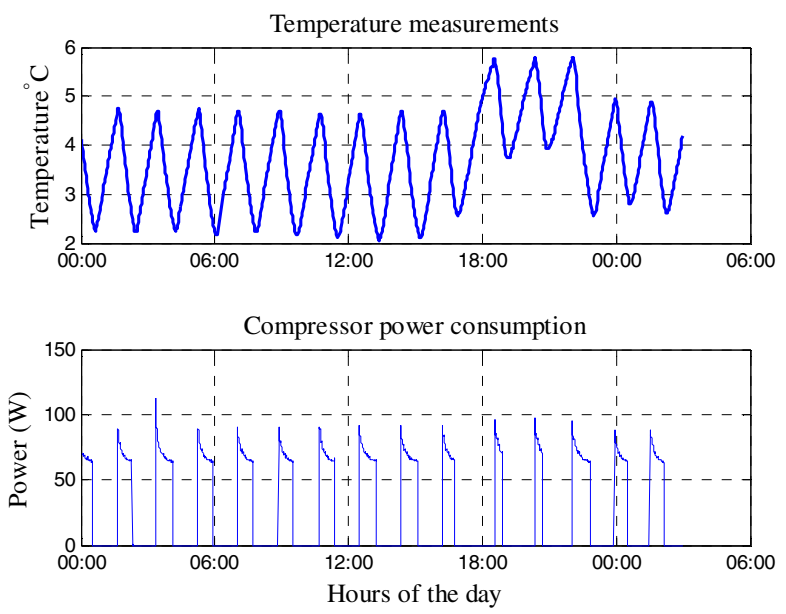

Fig. 5 Temperature variation inside the fridge and the power consumption.

The demand response control is activated for a period of three hours in the evening from $8 \mathrm{pm}$ till $11 \mathrm{pm}$ local time. The time for demand response activation is selected in a way that the users have less interaction with the refrigerator and at the same time they are aware of the control. To register the maximum and minimum threshold temperature, at least one cycle of each cooling and heating are required. The measurements from the fridges were started one day prior to the actual control period. Different fridges have different temperature set points. A fixed temperature rise during demand response may violate the temperature set point a lot, which may spoil the food stored and cause in convenience to the user. So it was decided to rise the temperature corresponds to half of the band between the higher and lower thresholds as shown in Fig. 5. In a normal operation, the control loop runs every two minutes. The control loop for each fridge is driven by the temperature measurement data as it is received every two minutes. If the user opens the fridge, the occupancy sensor sends a message about door opening and the fridge is switched $\mathrm{ON}$ if it is OFF and the five minutes duration after the previous switch OFF is elapsed.

\section{RESULT}

\section{A. Energy consumption calculation}

The experiment was conducted with 10 fridges for 9 days. All of the 10 fridges were not participating in the experiment on all of the days. The users have the flexibility to unsubscribe from the experiment on daily basis. The number of fridges participating in the experiment on each of the day is given in the TABLE I. If all of the 10 fridges were participating in a day, it is considered as $100 \%$ participation with participation factor of 1. Each day's participation factor is given in the TABLE I. The overall participation factor is the average of individual day's participation factor. The overall participation factor for the 9 days is 0.86 .

TABLE I

PARTICIPATION FACTOR

\begin{tabular}{|c|c|c|c|c|c|c|c|c|c|}
\hline Day & 1 & 2 & 3 & 4 & 5 & 6 & 7 & 8 & 9 \\
\hline $\begin{array}{c}\text { Number of } \\
\text { fridges }\end{array}$ & 10 & 9 & 9 & 10 & 8 & 7 & 8 & 6 & 10 \\
\hline $\begin{array}{c}\text { Participation } \\
\text { factor }\end{array}$ & 1 & 0.9 & 0.9 & 1 & 0.8 & 0.8 & 0.7 & 0.6 & 1 \\
\hline $\begin{array}{c}\text { Over all } \\
\text { participation } \\
\text { factor }\end{array}$ & \multicolumn{10}{|c|}{0.86} \\
\hline
\end{tabular}

The demand response activation period was $8 \mathrm{pm}$ till $11 \mathrm{pm}$ local time $(\mathrm{GMT}+1)$ in the month of February 2014. During demand response activation, the temperature of the cool chamber was maintained between higher threshold temperature (HT) and half of the temperature band above the higher threshold temperature. This method individualize the control for every fridge and enables same quality of service to all consumers. The active power consumption by the compressor is measured every 10 seconds and logged in the database. The temperature profile and power consumption of one of the fridges on control activation is shown in the Fig. 5

\section{A. Data integrity and inrush current}

The data integrity is checked for any discontinuity in the measurement. As every measurement values are logged with their synchronized server timestamp, the time difference between each power measurement from a particular refrigerator should be 10 seconds. All measurement from every fridge for the demand response activation period is continuous. As the compressor in the refrigerator is driven by single phase induction motor, there will be a high inrush current consumption during the compressor start up. The inrush current is typically 10 times the maximum current. The inrush current normally stays for 1 or 2 seconds and then fall to the nominal value corresponding to the load. If the power measurement instant synchronizes with compressor start up time, then there will be a high active power measurement due to the inrush current value. These high values of measured power causes a huge error in the energy calculation, as the 
power is measured once in ten seconds. For every fridge, the power measurements above full load values are clipped. The full load power is identified from the previous compressor cycles. The energy consumption during the demand response activation period is calculated by integrating the measured power over demand response activation period which is 3 hours in this case. The energy consumption by individual fridges was summed to get the aggregated consumption. The error in the estimate is found by subtracting the actual consumption from the estimate. The error percentage is calculated by considering the estimate as base. The error percentage in estimation is plotted for all days and show in the Fig. 8. The resulting estimation errors and the possible causes are discussed in the next section.

\section{B. Discussion}

The aggregated actual energy consumption for the three periods before (Pre DR), after (Post DR) and during DR activation for the fridges for 9 days are given in the Fig. 6 .

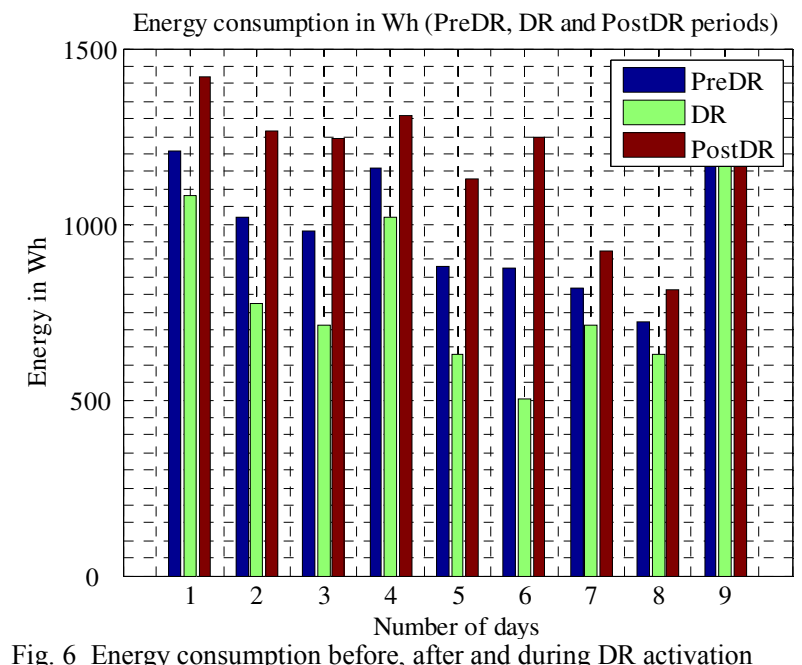

The time periods for the Pre DR and Post DR periods were taken 3 hours similar to the DR activation period. From the Fig. 6, it is evident that there is an energy reduction on DR activation by elevating the temperature of the fridge cool chamber. The reduced energy is consumed back in the Post DR period as a payback. The aggregated estimated and actual energy consumption is shown in the Fig. 7. For most of the days, the estimation is close to the actual consumption. The error percentage in the aggregated energy estimation is shown in Fig. 8. The error in estimation is less than $10 \%$ for all of the days. The percentage error in each cooling cycle time prediction of every individual fridge during the DR activation time is calculated from their actual cooling cycle time and presented in the Fig. 9. The number of cooling cycles between the fridges and between different days will depends on their individual thermal mass and system dynamics.

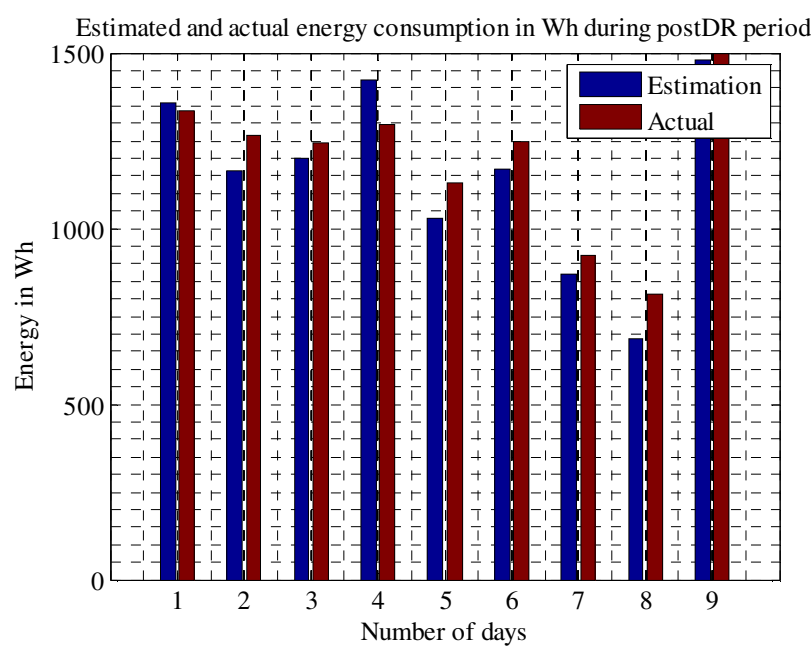

Fig. 7 Estimated and actual energy in Post DR period

In total, there are 118 cooling cycles during DR activation period from the fridges those participated in the experiment. The percentage error in each cooling cycle is very less. The histogram of cycle by cycle prediction error is shown in Fig. 10. The maximum error is 4.67. The mean value of percentage prediction error is 0.35 and the standard deviation is 2.5 .

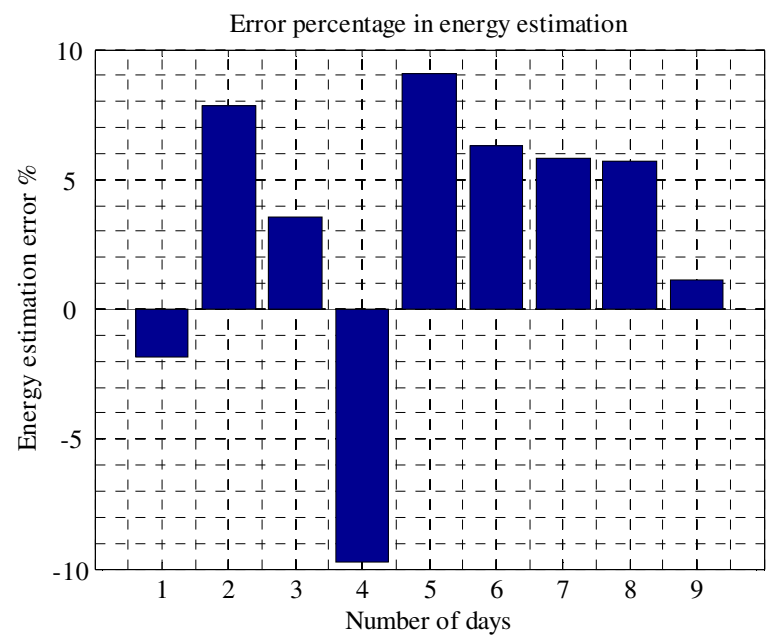

Fig. 8 Energy estimation error in of energy in Post DR period

Out of 118 values, 3 were very high which were around $10 \%, 11 \%$ and $25 \%$ respectively. Such huge error was due to temperature measurement data loss during the last cooling cycle before DR activation period. Those values were excluded for the statistical test, as they don't fit in the set under test. TABLE II shows the maximum, minimum, mean and standard deviation of the errors.

TABLE II

CYCLE BY CYCLE ESTIMATION ERROR

\begin{tabular}{|c|c|c|c|c|}
\hline $\begin{array}{c}\text { Number of } \\
\text { cycles }\end{array}$ & Maximum & Minimum & Mean & $\begin{array}{c}\text { Standard } \\
\text { Deviation }\end{array}$ \\
\hline 118 & 4.67 & -1.00 & 0.36 & 2.76 \\
\hline
\end{tabular}




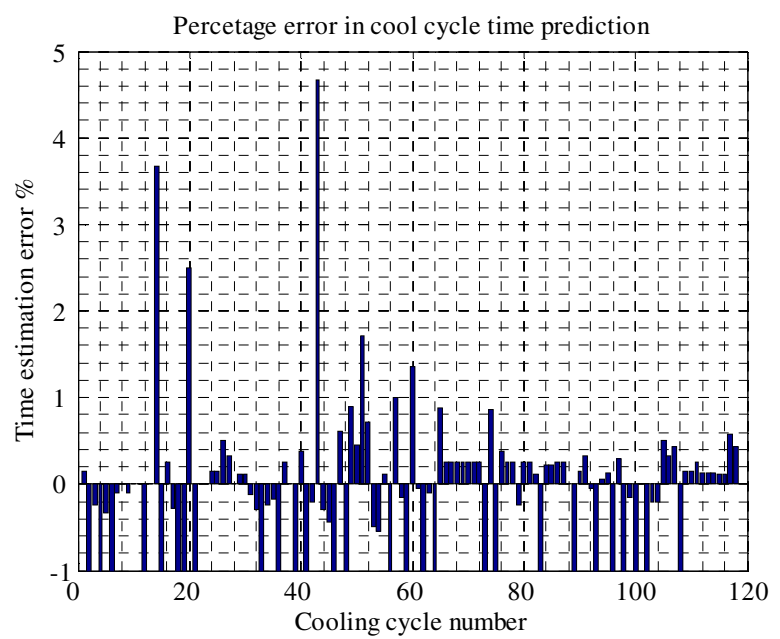

Fig. 9 Time estimation error in each cooling cycle during DR period.

Though the prediction error in the individual cooling cycle is very less, the error in aggregated energy estimation is higher. This is due to the additional compressor operation for short durations on fridge door openings. The controller activates the power to the refrigerator to illuminate the light bulb when the user opens the refrigerator's door. This power activation also starts the compressor.

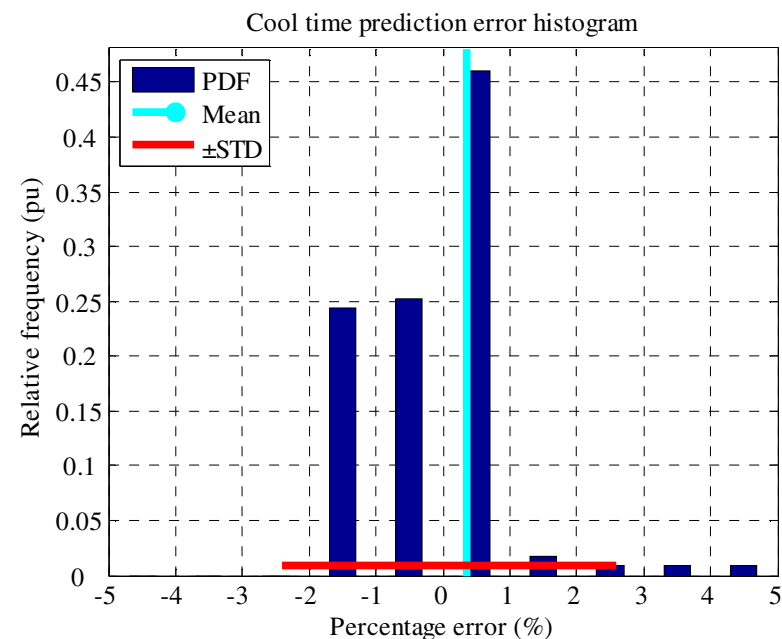

Fig. 10 Histogram of cool cycle time prediction error

The activated power is not cut-off for 5 minutes, to avoid multiple compressor start-ups, if the door is opened multiple times with in these 5 minutes.

\section{CONCLUSION}

This papers main idea is to estimate the energy shift by demand response activation on set of fridges in real domestic household. The amount of energy shift is estimated by estimating the consumption by the fridges on operating elevated temperature band. The method used is a simple and produces results with error limit of $\pm 10 \%$ in energy estimation on nominal conditions. The user interactions and change in refrigerator dynamics influence the estimation and push the error limits away from zero. This method is suited best for field experiments in which large numbers of domestic fridges are controlled. Operating the fridge in an elevated temperature band definitely reduce its energy consumption. At the same time the reduced consumption is paid back once the control is released. The estimation of cool and heat cycle duration can help to identify the time at which the compressor will be $\mathrm{ON}$ and $\mathrm{OFF}$, which can be used to find available power with the population of fridges at any time. By identifying the available power at any time, a further study can be done to utilize these fridges for network congestion management. Another possible study can be to utilize these fridges for voltage and or frequency control in an island distribution grid.

\section{REFERENCES}

[1] Danish Energy Agency. "Energy policy report 2012", Tech. Rep. 2011.

[2] Danish Ministry of Climate, Energy and Building. "Energy policy report 2012", Tech. Rep. May 2012

[3] M. Marinelli, F. Sossan, G. T. Costanzo, and H. W. Bindner, "Testing of a Predictive Control Strategy for Balancing Renewable Sources in a Microgrid," Sustainable Energy, IEEE Transactions on, vol.PP, no.99, pp.1-8, Jan. 201

[4] F. Sossan and H. Bindner, "Evaluation of the Performance of Indirect Control of many DSRs Using Hardware-in-the-loop Simulations". In Decision and Control (CDC2012), IEEE 51st Annual Conference on (pp. 5586-5591). 2012.

[5] M. Hoeven, "Nordic Energy Technology Perspectives: Pathways to a Carbon Neutral Energy Future" 2013 Nordic Energy Technology Perspectives OECD/IEA. Tech. Rep. 2013.

[6] M.M Almenta, J. Morrow, R. Best, and B. Fox, "Assessment of domestic load suitable for Smart Consumer Load Participation," Power Engineering Conference (UPEC), 2013 48th International Universities' , vol., no., pp.1,6, 2-5 Sept. 2013

[7] J. Hastings, D. Laverty, and D. J. Morrow, "A smart grid information system for demand side participation: Remote control of domestic appliances to balance demand," Power Engineering Conference (UPEC), 2013 48th International Universities' , vol., no., pp.1,5, 2-5 Sept. 2013

[8] J. A. Short, D.G. Infield, and L. L. Freris. "Stabilization of grid frequency through dynamic demand control." Power Systems, IEEE Transactions on 22.3 (2007): 1284-1293.

[9] V. Lakshmanan, M. Marinelli, A. M. Kosek, F. Sossan, and P. Norgard, "Domestic refrigerators temperature prediction strategy for the evaluation of the expected power consumption," Innovative Smart Grid Technologies Europe (ISGT EUROPE), 2013 4th IEEE/PES , vol., no., pp.1,5, 6-9 Oct. 2013.

[10] A. J. Roscoe, and G. Ault. "Supporting high penetrations of renewable generation via implementation of real-time electricity pricing and demand response." IET Renewable Power Generation 4.4 (2010): 369382.

[11] G.T. Costanzo, F. Sossan, M. Marinelli, P. Bacher and H. Madsen, "Grey-box Modeling for System Identification of Household Refrigerators: a Step Toward Smart Appliances", IYCE 2013, Sofiok, Jun 2013.

[12] F. Sossan, V. Lakshmanan, G. T. Costanzo, M. Marinelli, P.J. Douglass, and H. W. Bindner, "Thermal Modelling of a Household Refrigeration Unit for Smart Grids Applications," Smart Grid, IEEE Transactions on, submitted for publication. 